\title{
Cardiopulmonary health indices and diabetes risk scores in undergraduate students of a private university in Nigeria
}

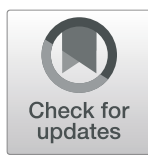

JolaOluwa Oluwatosin Yesufü*, Olaoluwa David Oluwasile², Olufemi Idowu Oluranti², Adesoji Adesipe Fasanmade ${ }^{1,3}$ and Ayodele O. Soladoye ${ }^{2}$

\begin{abstract}
Background: Cardiopulmonary health and its relationship with diabetes mellitus are very important but particularly underexplored in young undergraduate students of private Universities in Nigeria. This observational study investigated the effect of diabetic risk on cardiopulmonary health indices among healthy, consenting undergraduate students of a private university in Nigeria by a convenient sampling method. Cardiopulmonary health indices were assessed by anthropometry; cardiorespiratory fitness was determined by maximum oxygen uptake levels $\left(\mathrm{VO}_{2}\right.$ max), blood pressure and heart rates were measured using the Bruce treadmill protocol; oxygen saturation was determined by pulse oximetry, pulmonary function was assessed by spirometry; diabetes mellitus was risk determined by fasting blood glucose levels and the FINDRISC (Finish Diabetes Risk Score questionnaire which is a validated tool, for determining Diabetes risk; heart health awareness was determined by a modification of the healthy heart questionnaire (HHQ-GP-1) which is a standardized tool for heart health awareness and practices.
\end{abstract}

Results: Results showed that the prevalence of diabetes risk was 38.8\% in the sample population. The healthy heart questionnaire revealed that participants had poor diet (76\%) or did little or no exercise (60\%) and were also ignorant of what a normal blood pressure should be (72\%). There was no significant difference between blood pressure (systolic and diastolic) and heart rates after physical exercise of those at diabetes risk and those not at risk $(p>0.05)$. Fasting blood glucose levels between those at diabetes risk and those not at risk was significantly different $(p<0.01)$. The cardiorespiratory fitness $\left(\mathrm{VO}_{2} \max \right)$ of those not at diabetic risk was not significantly higher than of those at risk ( $p>0.385$ ). Respiratory functions (vital capacity, forced vital capacity, and forced expiratory volume) of those not at diabetic risk were higher than those at risk, showing that diabetes may impair lung function. Though this was not statistically significant $(p>0.05)$, the result obtained cannot be disregarded.

Conclusion: Universities and higher institutions of learning should incorporate regular health promotion and education programs that focus more on healthy lifestyles, physical exercise, and proper diet.

Keywords: Cardiopulmonary health indices, Cardiorespiratory fitness, Heart health awareness, Diabetes risk scores, Lung function, Undergraduate students

\footnotetext{
* Correspondence: johlah18@gmail.com

${ }^{1}$ Department of Physiology, Faculty of Basic Medical Sciences, College of

Medicine, University of Ibadan, Ibadan, Nigeria

Full list of author information is available at the end of the article
} 


\section{Background}

Diabetes mellitus (DM), commonly referred to as diabetes, is a group of metabolic disorders in which there are high blood sugar levels over a prolonged period [1]. Diabetes is due to either the pancreas not producing enough insulin or the cells of the body not responding properly to the insulin produced [2]. Over time, diabetes mellitus (DM) has emerged as a global healthcare problem that has reached epidemic proportions [3]. In 2019, approximately 463 million adults (20-79 years) are living with diabetes; by 2045 this will rise to 700 million. The proportion of people with type 2 diabetes is increasing in most countries, while $79 \%$ of adults with diabetes live in low- and middle-income countries. One (1) in two (2) (232 million) people with diabetes remain undiagnosed [4]. Type 2 diabetes is the most common type of diabetes, accounting for approximately $90 \%$ of all diabetes cases [5]. Diabetes is one (1) of four (4) priority noncommunicable diseases (NCDs) targeted by world leaders [6].

In Africa, where infectious diseases have traditionally been the focus of healthcare systems, diabetic cases are expected to increase by $90 \%$ in 2030 [7]. At least $78 \%$ of people in Africa are undiagnosed and do not know they are living with diabetes and the number of people living with diabetes is expected to rise from 366 million in 2011 to 552 million by 2030, if no urgent action is taken $[7,8]$.

Beyond the effect of smoking, poor lung functions have been long found to have a relationship with other important health outcomes [9]. One of these important relationships is the complex interaction between diabetes and lung functions. Cross-sectional studies have found that patients with diabetes tend to have poorer lung functions than non-diabetics [10-12]. Lung functions parameters can be used for predicting morbidity and mortality [13]. Reduced pulmonary functions in patients with metabolic syndrome and diabetes have been observed in both cross-sectional and prospective studies [14-16]. Microangiopathy, systemic low-grade inflammation, autonomic neuropathy, and diminished respiratory muscle functions have been proposed as possible causes of decreased pulmonary function in diabetics [17]. Cardiorespiratory fitness, as assessed by measuring peak oxygen consumption (VO2) and other measurements that were obtained through cardiopulmonary exercise testing, is an independent predictor of mortality in patients with cardiovascular disease [18], which also allows for an objective assessment of functional performance and physical exercise capacity [19].

The majority of type 2 DM cases, which is a potentially preventable disease, progress over nearly a decade of asymptomatic phase of pre-diabetes during which clinically identifiable risk factors are apparent [20].
Diabetes risk score tools which are usually cost-effective provide an economical and convenient alternative to mass screening using laboratory-based diagnostic tests. According to the International Diabetes Federation, the Finnish Diabetes Risk Score (FINDRISC) is the most valid and inexpensive tool preferred for resource limited settings [4]. FINDRISC was derived in a 10-year prospective study for identification of people at high risk of future occurrence of type 2 DM among the Finnish population [21].

The current generation of adolescents and young adults, who have been more influenced by information and communication technology, differ greatly from their parents in terms of health awareness, food fads, habits, and other cardiopulmonary modifiable risk factors. No known study has investigated the effect of diabetic risk on cardiopulmonary health indices among healthy undergraduate students of private Universities in Nigeria. Therefore, the present study was undertaken in the young student population of a private University.

\section{Methods}

\subsection{Description of study area}

The private University was located in South-West Nigeria.

\subsection{Study design}

A descriptive study in which one of the private Universities in South-West Nigeria was selected.

\subsection{Study participants}

A total of 25 apparently healthy male and female consenting students of the Private University, participated in the study. Written informed consent was obtained.

\subsection{Exclusion criteria}

This includes those who are smokers, alcoholics, asthmatics, and ill.

\subsubsection{Anthropometric data}

The height and weight measurements were obtained with a measuring tape and a weighing scale respectively. Body mass Index (BMI) was calculated from the values of height and weight using the following formula: weight $(\mathrm{kg}) /$ height $^{2}\left(\mathrm{~m}^{2}\right)$.

\subsubsection{Healthy heart questionnaire}

Participants responded to a modified version of the Healthy heart questionnaire [22]. The purpose of the questionnaire was to investigate healthy heart awareness, diet, and exercise/physical activity of the participants. 


\subsubsection{Finnish diabetes risk score (FINDRISC)}

It is a simple, fast, inexpensive, non-invasive, and reliable tool to identify individuals at high risk for type $2 \mathrm{DM}$ $[21,23]$. Participants completed the FINDRISC questionnaire, and their scores were determined along with their fasting blood glucose levels. The items on the FINDRISC questionnaire are as follows:

The current 8 -item ( $0-26$ point) FINDRISC scale that was used in this original research consists of the following:

1. Age; minimum point $=0$, maximum point $=4$

2. Body mass index: minimum point $=0$, maximum point $=3$

3. Waist circumference in both male and female: minimum point $=0$, maximum point $=4$

4. Physical activity: minimum point $=0$, maximum point $=2$

5. Frequency of consumption of fruits/ vegetables: minimum point $=0$, maximum point $=1$

6. Ever taken medication for high blood pressure on a regular basis: minimum point $=0$, maximum point $=2$

7. Ever been found to have high blood glucose during a health examination, illness or pregnancy?: minimum point $=0$, maximum point $=5$

8. Any immediate family members or other relatives been diagnosed with either Type1 or Type 2 Diabetes?: minimum point $=0$, maximum point $=5$ (The FINDRISC questionnaire [24]) is available at https://www.diabetes.fi/files/502/eRiskitestilomake. pdf;

The following FINDRISC values were the benchmark for assessment (Table 1).

\subsection{Fasting blood sugar test}

The fasting blood glucose of all participants was measured between the periods of 7 A.M.-10 A.M., using a glucometer (Double G sugar monitor glucose meter). Diabetes was diagnosed based on fasting blood glucose in accordance with internationally recognized criteria by the American diabetes association: normal, $<100 \mathrm{mg} / \mathrm{dL}$;

Table 1 Values of FINDRISC, description and prognosis

\begin{tabular}{lll}
\hline FINDRISC values & Description & Prognosis \\
\hline 7 & Low & 1 in 100 will develop disease \\
$7-11$ & Slight elevation & 1 in 25 will develop disease \\
$12-14$ & Moderate & 1 in 6 will develop disease \\
$15-20$ & High & 1 in 3 will develop disease \\
$>20$ & Very High & 1 in 2 will develop disease \\
\hline
\end{tabular}

Summary: Score 7: not at risk

Score > 7-20: people at risk pre-diabetes, $100-125 \mathrm{mg} / \mathrm{dL}$; diabetes mellitus, $\geq 126$ $\mathrm{mg} / \mathrm{dL}[25]$.

\subsection{Cardiopulmonary fitness}

Cardiopulmonary fitness was carried out using a treadmill (Lepow Huikang running HL1360J treadmill home fitness folding multifunction Electric genuine). Participants were subjected to run on the treadmill starting on the lowest speed $(1.0 \mathrm{mph})$ and increasing the speed (by $2 \mathrm{mph}$ ) at intervals of $3 \mathrm{~min}$. This was done until the participants were unable to run anymore at which point the treadmill was stopped and the time through which each individual could withstand; the test was recorded. The $\mathrm{VO}_{2}$ max was calculated using the formula:

- For men, $\mathrm{VO}_{2} \max =14.8-(1.379 \times \mathrm{T})+(0.451 \times$ $\left.\mathrm{T}^{2}\right)-\left(0.012 \times \mathrm{T}^{3}\right)$

- For women, $\mathrm{VO}_{2} \max =4.38 \times \mathrm{T}-3.9$, where $\mathrm{T}=$ Total time on the treadmill measured as a fraction of a minute

\subsection{Blood pressure and heart rate}

The blood pressure and heart rate were measured and recorded before and after the fitness exercise using a Digital sphygmomanometer (Omron HEM-7120 Automatic Blood Pressure Monitor; Omron Health care Europe B.V). The digital sphygmomanometer was standardized against the mercury in glass sphygmomanometer (Accousson).

\subsection{Oxygen consumption}

The Oxygen consumption or saturation for participants was measured and recorded before and after the physical fitness exercise using pulse oximetry (Blue Jay Comfort Finger Tip Pulse Oximeter).

\subsection{Spirometry}

The vital capacity, forced vital capacity (FVC), and forced expiratory volume $\left(\mathrm{FEV}_{1}\right)$ were measured before and after the exercise using a Vitalograph (Vitalograph ALPHA Desktop Spirometer). The subjects were properly trained for the lung functions test. This was achieved by asking the participants to breathe forcefully into the mouth piece three times for the vital capacity and forced vital capacity and three times forcefully (prolonging their breath) to calculate the forced expiratory volume.

\section{Results}

\subsection{Diabetic risk score}

The prevalence of those at risk was $28 \%$ (7). 
Table 2 Anthropometric data of both groups (participants at risk and those not at risk)

\begin{tabular}{lll}
\hline Variable & Participants at risk & Participants not at risk \\
\hline Age (years) & $21.1 \pm 1.67$ & $22.5 \pm 0.80$ \\
Weight $(\mathrm{Kg})$ & $72.9 \pm 4.83$ & $66.1 \pm 2.49$ \\
Height $(\mathrm{M})$ & $1.7 \pm 0.03$ & $1.7 \pm 0.02$ \\
Body mass index $\left(\mathrm{Kg} / \mathrm{m}^{2}\right)$ & $24.5 \pm 0.97$ & $20.3 \pm 0.28$ \\
$\mathrm{n}$ & 7 & 18 \\
\hline
\end{tabular}

$n$ number of participants

Values are expressed as mean \pm SEM.

\subsection{Anthropometric data (Table 2)}

A greater proportion of the respondents 18 (72.0\%) had their body mass index lower than 25, However, 6 (24.0\%) of the respondents had a body mass index of 25-30, while 1 (4.0\%) had a body mass index of $\geq 30$ (Figs. 1, 2, and 3).

\subsection{Cardiorespiratory function (Table 3)}

\subsection{Diabetes risk score (DRS) and fasting blood sugar (FBS) result (Table 4)}

\subsection{Spirometry (Table 5)}

\section{Discussion}

In the present study, we sought to investigate the relationship between diabetes risk scores and cardiopulmonary health indices in healthy undergraduate students of a private University in South-western Nigeria.

The results of the study showed that the diabetes risk score had significant effect on only the fasting blood sugar level $(p<0.01)$. The diabetes risk was determined using the Finnish Diabetes Risk Score (FINDRISC) questionnaire. Information supplied by participants, in the healthy heart questionnaire, showed that poor diet and lack of physical exercise were prevalent.

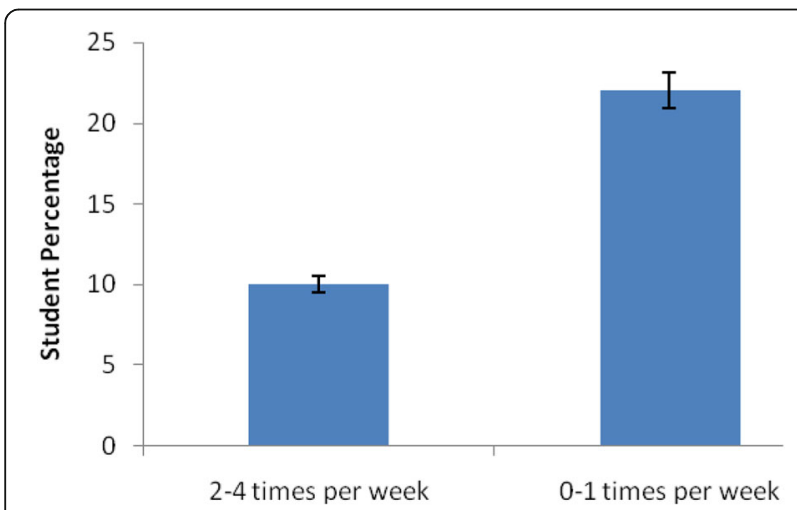

Fig. 1 Frequency of exercise (10 \pm 0.5 reported 2-4 times per week, while $22 \pm 1.1$ reported $0-1$ times per week)

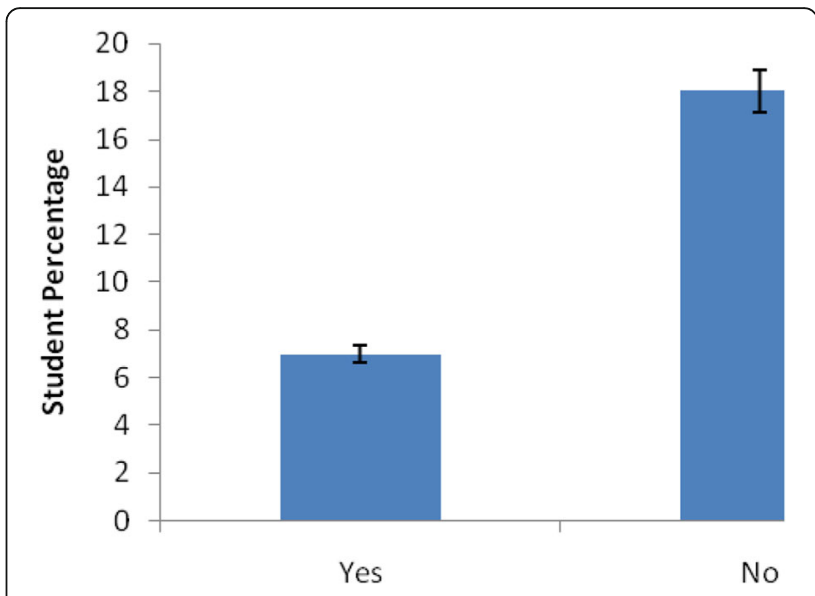

Fig. 2 is systolic blood pressure of $140 \mathrm{mmHg}$ high? $(7 \pm 0.35$ reported "YES" while $18 \pm 0.9$ reported "NO")

Students with high risk scores had significantly higher blood glucose levels and higher body mass index (BMI) than those not at risk.

This infers that higher diabetes risk scores are associated with higher body mass index. Similarly, other studies had found that subjects with high risk for type 2 diabetes mellitus had higher BMI, blood glucose, basal insulin, HOMA-IR (insulin resistance), and lower HDL$C$ (high density lipoprotein), than those with lowmoderate risk for type 2 diabetes $[26,27]$. They also reported that subjects at high risk according to FINDRISC were 4.8 times more likely to develop metabolic syndrome than those at low risk. Hence, FINDRISC is not only a tool which detects type 2 diabetes mellitus, but also one to identify subjects with elevated global cardiometabolic risk.

Blood pressure and heart rate were not significantly different between students at diabetic risk and those without or at low risk. The cardiorespiratory fitness $\left(\mathrm{VO}_{2} \max \right)$ of those not at risk was higher than of those

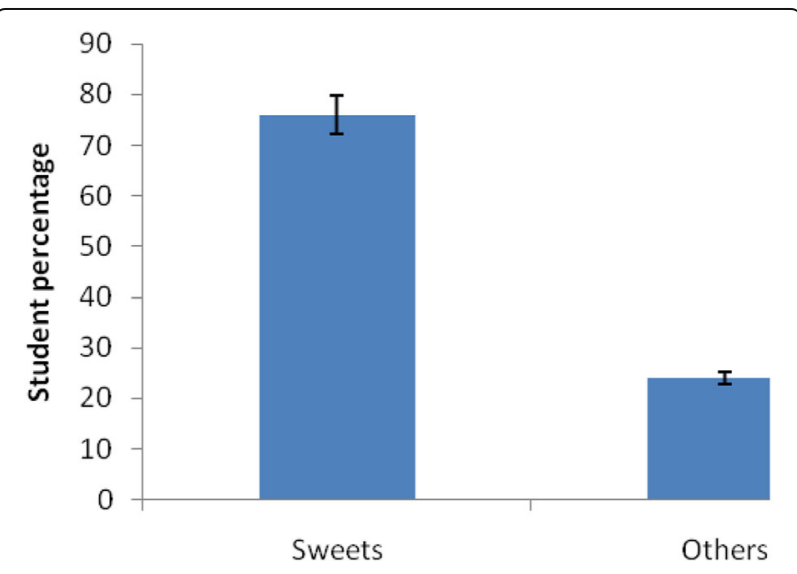

Fig. 3 Types of snacks eaten (sweets: $76 \pm 3.8$; others: $24 \pm 1.2$ ) 
Table 3 Cardiorespiratory data of both groups (participants at risk and those not at risk)

\begin{tabular}{llll}
\hline Variable & Participants at risk $(n=7)$ & Participants not at risk $(n=18)$ & $P$ value \\
\hline Systolic blood pressure before $(\mathrm{mmHg})$ & $120 \pm 6.26$ & $119.6 \pm 2.22$ & 0.948 \\
Systolic blood pressure after $(\mathrm{mmHg})$ & $132.6 \pm 3.66$ & $135.9 \pm 3.41$ & 0.517 \\
Diastolic blood pressure before $(\mathrm{mmHg})$ & $68.9 \pm 3.45$ & $74.9 \pm 2.55$ & 0.185 \\
Diastolic blood pressure after $(\mathrm{mmHg})$ & $68 \pm 4.97$ & $73.4 \pm 2.61$ & 0.231 \\
Heart rate before (BPM) & $82.7 \pm 3.80$ & $78.2 \pm 2.60$ & 0.349 \\
Heart rate after (BPM) & $118.6 \pm 3.80$ & $114.3 \pm 5.47$ & 0.755 \\
Oxygen consumption before $(\mathrm{mmHg})$ & $97.4 \pm 0.46$ & $97 \pm 0.498$ & 0.963 \\
Oxygen consumption after $(\mathrm{mmHg})$ & $97.1 \pm 0.55$ & $97.3 \pm 0.463$ & 0.854 \\
Cardiorespiratory fitness $\left(\mathrm{VO}_{2} \mathrm{max}\right)$ & $25.1 \pm 4.05$ & $30.5 \pm 4.62$ & 0.385 \\
\hline
\end{tabular}

$n$ number of participants

Values are expressed as mean \pm SEM. There was no significant difference in Systolic and diastolic blood pressures, heart rates, Oxygen consumption and $\mathrm{VO}_{2}$ max of both groups of students

at risk. This buttresses the importance of physical fitness via physical exercise, in the prevention of diabetes, and shows that those at risk of diabetes (usually with high BMI) have very low cardiopulmonary fitness. Responses from the healthy heart questionnaire showed that students at diabetic risk were ignorant of importantly specific health information associated with their cardiovascular system (for example normal blood pressure).

Reduced lung function is associated with a diminished capacity of maximum oxygen uptake, which is considered to be the best measure of cardiorespiratory fitness and physical exercise capacity [28]. Despite these diabetes-related reductions in the ability to oxygenate and deliver blood to peripheral tissues, some studies have found that $\mathrm{VO}_{2}$ max is not different between subjects with type I diabetes and subjects without diabetes when matched for age, sex, body composition, and physical activity $[29,30]$. In this current research among University students, respiratory functions (vital capacity, forced vital capacity and forced expiratory volume) of those not at risk was higher than those at risk, showing that diabetes may impair lung functions. Similarly, there are quite a number of studies that have assessed poor lung functions in relation to diabetes or pre-diabetes risk [31-35]. It has also been reported that decreased lung

Table 4 DRS and FBS data of both groups (participants at risk and those not at risk). Values are expressed as mean \pm SEM, $n$ number of participants

\begin{tabular}{llll}
\hline Variable & $\begin{array}{l}\text { Participants } \\
\text { at risk }(n=7)\end{array}$ & $\begin{array}{l}\text { Participants not } \\
\text { at risk }(n=18)\end{array}$ & $P$ value \\
\hline Diabetes risk score & $10.3 \pm 1.38$ & $4.1 \pm 0.589$ & $<0.004$ \\
$\begin{array}{l}\text { Fasting blood sugar } \\
(\mathrm{mmHg})\end{array}$ & $100.5 \pm 3.68$ & $89.4 \pm 1.42$ & $<0.001$ \\
$n$ & 7 & 18 & \\
\hline $\begin{array}{l}\text { There is a significant difference }(p<0.05) \text { between the means of DRS and FBS } \\
\text { in both groups }\end{array}$
\end{tabular}

Table 5 Spirometry of participants at diabetic risk and those not at risk

\begin{tabular}{llll}
\hline Variable & $\begin{array}{l}\text { Participants } \\
\text { at risk }(n=7)\end{array}$ & $\begin{array}{l}\text { Participants not } \\
\text { at risk }(n=18)\end{array}$ & $P$ value \\
\hline $\begin{array}{c}\text { Vital capacity } \\
\text { Before }\end{array}$ & & & \\
Normal & $3.8 \pm 0.35$ & $4.1 \pm 0.20$ & 0.591 \\
Best & $3.4 \pm 0.26$ & $3.5 \pm 0.21$ & 0.652 \\
& & After & \\
Normal & $4.6 \pm 0.33$ & $4.9 \pm 0.20$ & 0.656 \\
Best & $4.0 \pm 0.30$ & $4.3 \pm 0.20$ & 0.712 \\
& Forced vital capacity (FVC) & \\
Before & $3.8 \pm 0.31$ & $4.0 \pm 0.17$ & 0.547 \\
Normal & $3.6 \pm 0.29$ & $3.8 \pm 0.19$ & 0.763 \\
Best & & & \\
& $4.4 \pm 0.24$ & $4.7 \pm 0.18$ & 0.602 \\
Normal & $4.2 \pm 0.24$ & $4.4 \pm 0.19$ & 0.509 \\
Best & &
\end{tabular}

Forced expiratory volume (FEV 1 )

\begin{tabular}{llll}
$\begin{array}{l}\text { Before } \\
\text { Normal }\end{array}$ & $3.4 \pm 0.18$ & $3.4 \pm 0.13$ & 0.796 \\
Best & $3.0 \pm 0.18$ & $3.1 \pm 0.17$ & 0.643 \\
& \multicolumn{3}{c}{ After } \\
Normal & $3.8 \pm 0.14$ & $4.0 \pm 0.186$ & 0.632 \\
Best & $3.6 \pm 0.18$ & $3.6 \pm 0.02$ & 0.484 \\
\hline $\begin{array}{l}\text { V number of participants } \\
\text { Values are expressed as mean } \pm \text { SEM. Vital capacity forced vital capacity and } \\
\text { showed no significant difference }\end{array}$
\end{tabular}


functions observed among diabetics may be explained by collagen accumulation in the lung connective tissue [15]. Respiratory impairment among persons with diabetes might be influenced by increased body mass index (BMI) and result in fat deposits between the muscles and the ribs, which decrease chest wall compliance and weaken the respiratory muscles [36].

\section{Conclusion}

This study investigated the cardiopulmonary health indices and diabetes risk scores of undergraduate students in a private University in Nigeria. Students at risk of diabetes mellitus (assessed with the FINDRISC) actually had high fasting glycemia levels and lower respiratory functions (assessed by spirometry) than those not at risk.

The influence of western diets and dietary habits in the wake of urbanization has aggravated the morbidity and mortality associated with non-communicable diseases such as diabetes mellitus. Preventive measures should be initiated early from childhood and young adulthood to turn down the trend of the diabetes pandemic. Universities and higher institutions of learning should initiate more in depth health screening at the point of admission as well as yearly. This would ensure proper health interventions and follow up where necessary. Healthy lifestyles, physical exercise, and diet ought to be promoted in more creative ways during regular health education of the students.

\section{Abbreviations}

BMI: Body mass index; DM: Diabetes Mellitus; DRS: Diabetes risk score FBS: Fasting blood sugar; FEV 1 : Forced expiratory volume 1; FINDRISC: Finnish Diabetes Risk Score; FVC: Forced vital capacity; NCD: Non-communicable diseases

\section{Acknowledgements}

Authors acknowledge the university authorities of the Department of Physiology and the fitness/wellness center.

\section{Authors' contributions}

This research concept, design, and development were by JOY and AAF, as well as supervised by AAF and AOS. ODO was responsible for data collection and analysis. The manuscript was majorly written and edited by both JOY and OIO. All authors read and approved the final manuscript.

\section{Funding}

Not applicable.

\section{Availability of data and materials} Not applicable.

\section{Ethics approval and consent to participate}

This study in a private University among undergraduate students was approved by the Ethical committee of the University's Teaching Hospital in South-West Nigeria. BUTH (Bowen University teaching Hospital) Research committee Registration Number NHREC/12/04/2012 MANUSCRIPT APPROVAL NUMBER: BUTH/REC-032. Informed written consent to participate was obtained from study participants.

\section{Consent for publication}

Not applicable.

\section{Competing interests}

The authors declare that they have no competing interests.

\section{Author details}

'Department of Physiology, Faculty of Basic Medical Sciences, College of Medicine, University of Ibadan, Ibadan, Nigeria. ${ }^{2}$ Department of Physiology, Faculty of Basic Medical Sciences, College of Health Sciences ", Bowen University, Iwo, Nigeria. ${ }^{3}$ Department of Medicine, Faculty of Clinical Sciences, College of Medicine, University of Ibadan, Ibadan, Nigeria.

Received: 15 November 2019 Accepted: 27 December 2019 Published online: 13 February 2020

\section{References}

1. World Health Organization (2016) Global report on diabetes. WHO, Geneva

2. Shoback, edited by David G. Gardner, Dolores. "Chapter 17". Greenspan's basic \& clinical endocrinology (9th Ed.). New York: McGraw-Hill Medical. ISBN 0-07-162243-8; 2011

3. Alebiosu CO, Familoni O, Ogunsemi O, Raimi TH, Balogun W, Odusan O et al (2009) Strategies for improving diabetes care in Nigeria (SIDCAIN) Research Group. Methods Study Protoc Niger Endocr Pract 3:13-26

4. International Diabetes Federation (2019) IDF Diabetes Atlas, 9th edn, Brussels Available at: http://www.diabetesatlas.org

5. International Diabetes Federation 2019. Type 2 Diabetes. https:/wwww.idf.org

6. World Health Organization 2016. Global report on Diabetes. http://www. who.int.

7. Shi Y, Hu FB (2014) The global implications of diabetes and cancer. Lancet 383(9933):1947-1948

8. Vos T, Flaxman AD, Naghavi M, Lozano R, Michaud C, Ezzati M, Shibuya K, Salomon JA, Abdalla S, Aboyans $V$ et al (2012) Years lived with disability (YLDs) for 1160 sequelae of 289 diseases and injuries 1990-2010: a systematic analysis for the global burden of disease study 2010. Lancet 380(9859):2163-2196

9. International diabetes foundation. Diabetes atlas Available from: http:// www.idf.org/diabetesatlas/

10. Alebiosu OC, Familoni OB, Ogunsemi OO, Raimi TH, Balogun WO, Odusan O et al (2013) Community based diabetes risk assessment in Ogun state, Nigeria (World Diabetes Foundation project 08-321). Indian J Endocr Metab 17:653-658

11. Schroeder EB, Welch VL, Couper D, Nieto FJ, Liao D, Rosamond WD, Heiss G (2003) Lung function and incident coronary heart disease: the Atherosclerosis Riskin Communities Study. Am J Epidemiol 158(12):1171-1181

12. Walter RE, Beiser A, Givelber RJ, O'Connor GT, Gottlieb DJ (2003) Association between glycemic state and lung function: the Framingham Heart Study. Am J Respir Crit Care Med 167(6):911-916

13. Yeh HC, Punjabi NM, Wang NY, Pankow JS, Duncan BB, Cox CE, Selvin E, Brancati FL (2008) Cross-sectional and prospective study of lung function in adults with type 2 diabetes: the Atherosclerosis Risk in Communities (ARIC) study. Diabetes Care 31(4):741-746

14. Chance WW, Rhee C, Yilmaz C, Dane DM, Pruneda ML, Raskin P, Hsia CC (2008) Diminished alveolar microvascular reserves in type 2 diabetes reflectsystemic microangiopathy. Diabetes Care 31(8):1596-1601

15. Young RP, Hopkins R, Eaton TE (2007) Forced expiratory volume in one second: not just a lung function test but a marker of premature death from all causes. Eur Respir J 30(4):616-622

16. Lange P, Parner J, Schnohr P, Jensen G (2002) Copenhagen City Heart Study: longitudinal analysis of ventilatory capacity in diabetic and nondiabetic adults. Eur Respir J 20:1406-1412

17. Litonjua AA, Lazarus R, Sparrow D, Demolles D, Weiss ST (2005) Lung function in type 2 diabetes: the normative aging study. Respir Med 99:1583-1590

18. Yeh F, Dixon AE, Best LG et al (2011) Obesity in adults is associated with reduced lung function in metabolic syndrome and diabetes: the Strong Heart Study. Diabetes Care 34(10):2306-2313

19. Klein OL, Krishnan JA, Glick S, Smith LJ (2010) Systematic review of the association between lung function and type 2 diabetes mellitus. Diabet Med 27:977-987

20. Chaudhry S, Arena R, Bhatt DL, Verma S, Kumar N (2018) A practical clinical approach to utilize cardiopulmonary exercise testing in the evaluation and management of coronary artery disease. Curr Opin Cardiol 33(2):168-177

21. Lindström J, Tuomilehto J (2003) The diabetes risk score: a practical tool to predict type 2 diabetes risk. Diabetes Care 26(3):725-731 
22. University of Colorado, Denver. Healthy heart questionnaire (HHQ-GP-1), available on www.ucdenver.edu.

23. Zaigham S, Nilsson PM, Wollmer P, Engström G (2016) The temporal relationship between poor lung function and the risk of diabetes. BMC Pulm Med 16:75

24. The FINDRISC questionnaire. Available at https://www.diabetes.fi/files/502/ eRiskitestilomake.pdf

25. Ross R, Blair SN, Arena R, Church TS, Despres JP, Franklin BA et al (2016) Importance of assessing cardiorespiratory fitness in clinical practice: a case for fitness as a clinical vital sign: a scientific statement from the American Heart Association. Circulation 134(24):653-699

26. Bertram MY, Vos T (2010) Quantifying the duration of pre-diabetes. Aust N Z J Public Health 34(3):311-314

27. American Diabetes Association (2019) Classification and diagnosis of diabetes: standards of medical care in diabetes. Diabetes Care 42(Supplement 1):S13-S28

28. Janghorbani M, Adineh H, Amini M (2013) Evaluation of the Finnish Diabetes Risk Score (FINDRISC) as a screening tool for the metabolic syndrome. Rev Diabet Stud 10:283-292

29. Đurić P, Mladenović Z, Grdinić A et al (2014) Correlation between the Finnish diabetes risk score and the severity of coronary artery disease. Vojnosanit Pregl 71:474-480

30. Köseoğlu B, Safer VB, Öken Ö, Akselim S (2016). Cardiovascular disease risk in people with spinal cord injury: is there a possible association between reduced lung function and increased risk of diabetes and hypertension? Spinal Cord 55, 87-93 (2017) https://doi.org/10.1038/sc.2016.101

31. Niranjan V, McBrayer DG, Ramirez LC, Raskin P, Hsia CC (1997) Glycemic control and cardiopulmonary function in patients with insulin-dependent diabetes mellitus. Am J Med 103(6):504-513

32. Gusso S, Hofman P, Lalande S, Cutfield W, Robinson E, Baldi JC (2008) Impaired stroke volume and aerobic capacity in female adolescents with type 1 and type 2 diabetes mellitus. Diabetologia 51(7):1317-1320

33. Engstrom G, Hedblad B, Nilsson P, Wollmer P, Berglund G, Janzon L (2003) Lung function, insulin resistance and incidence of cardiovascular disease: a longitudinal cohort study. J Intern Med 253(5):574-581

34. Heianza Y, Arase Y, Tsuji H, Saito K, Amakawa K, Hsieh SD, Kodama S, Shimano H, Yamada N, Hara S et al (2012) Low lung function and risk of type 2diabetes in Japanese men: the Toranomon Hospital Health Management Center Study 9 (TOPICS 9). Mayo Clin Proc 87(9):853-861

35. Yamane T, Yokoyama A, Kitahara Y, Miyamoto S, Haruta Y, Hattori N, Yamane K, Hara H, Kohno N (2013) Cross-sectional and prospective study ofthe association between lung function and prediabetes. BMJ Open 3(2):e002179

36. Kim CH, Kim HK, Kim EH, Bae SJ, Jung YJ, Choi J, Park JY (2015) Association of restrictive ventilatory dysfunction with the development of pre-diabetes and type 2 diabetes in Koreans. ActaDiabetol 52(2):357-363

\section{Publisher's Note}

Springer Nature remains neutral with regard to jurisdictional claims in published maps and institutional affiliations.

\section{Submit your manuscript to a SpringerOpen ${ }^{\circ}$ journal and benefit from:}

- Convenient online submission

- Rigorous peer review

- Open access: articles freely available online

- High visibility within the field

- Retaining the copyright to your article

Submit your next manuscript at $\boldsymbol{\nabla}$ springeropen.com 